\title{
Hyper-Homocysteinemia: A Potential Indicator of Acute Pancreatitis
}

\author{
Ling-Chun Zhang', Qiao-Yan Li' ${ }^{1}$, Jin-Xia Zhang ${ }^{1}$ and Lian-Cai Wang ${ }^{2 *}$ \\ ${ }^{1}$ Department of Pharmacy, Henan Provincial People's Hospital, Zhengzhou University, China \\ ${ }^{2}$ Department of Hepatobiliary Surgery, Henan Provincial People's Hospital, Zhengzhou University, China
}

\begin{abstract}
Objectives: Hyper-homocysteinemia, reportedly, is closely associated with some known vascular dysfunctions, thrombosis and even inflammations. However, till now rare studies were directed to the association between hyperhomocysteinemia and acute pancreatitis (AP). The illumination of this potential association is expected to benefit therapies of AP. In this regard, this study aims at digging the underlying association between hyper-homocysteinemia and AP.
\end{abstract}

Methods: In this study, 160 patients with AP were involved. The plasma levels of homocysteine of these patients were measured. The patients were divided into two groups, based on the serum homocysteine concentration. Patients with high plasma homocysteine concentrations $(C>15 \mu \mathrm{mol} / \mathrm{L})$ were classified as Group 1 , while the rest with normal plasma homocysteine concentrations $(5 \mu \mathrm{mol} / \mathrm{L} \leq \mathrm{C} \leq 15 \mu \mathrm{mol} / \mathrm{L})$ were identified as Group 2 . Then, the lipid levels for the two groups were studied to detect whether there existed a synergistic effect of hyper-homocysteinemia and hypertriglyceride on AP.

Results: Almost half $(46.9 \%)$ of the patients with AP were found to bear hyper-homocysteinemia in this study. However, patients in Group 1 were found to have lower triglyceride and total cholesterol levels than those in Group 2, with $\mathrm{P}=0.038$ and $\mathrm{P}=0.046$ respectively. In addition, more patients in Group 2 had hyper-triglyceride and hyper-total cholesterol than those in Group 1, though the differences were not significantly observed.

Conclusions: In conclusion, these studies showed that hyper-homocysteinemia may be a very important indicator of a high risk of AP. So, more attention should be paid to hyper-homocysteinemia in the progress of AP.

Keywords: Homocysteine; AP; Chinese population

\section{Introduction}

AP (AP) is a common disease that features auto-digestion of the pancreas, and is the second highest cause of total hospital stays, the largest contributor to aggregate costs, and the fifth leading cause of in-hospital deaths [1-4]. Furthermore, patients with pancreatitis reportedly bear higher risk of developing pancreatic cancer $[5,6]$. Biliary disease and excessive alcohol consumption are the most common reasons for AP, but acute and chronic recurrent pancreatitis have also been reported in patients with varieties of concurrent metabolic disorders involving hyperlipidaemias, branched-chain amino acid degradation, homocystinuria, haemolytic, acute intermittent porphyria and several amino acid transporter defects [7]. For instance, hyperlipidaemia is one of the most common causes of AP, and triglyceride (TG) levels above $11.3 \mathrm{mmol} / \mathrm{L}(1000 \mathrm{mg} / \mathrm{dl})$ are generally considered to put patients at high risks of developing pancreatitis $[8,9]$. Elevated plasma homocysteine concentrations had been reported to involve the development of arterial thrombosis and atherosclerosis [10]. Based on this point, high homocysteine levels may also be one cause of AP, endothelial dysfunction and impaired microvascular circulation. However, to date, little research was focused on the relationship between plasma homocysteine concentrations and AP $[11,12]$. Hence, we began our studies on the relationship between plasma homocysteine concentrations and AP and possibilities of the synergistic effect of plasma homocysteine levels and triglyceride levels on the occurrence of AP.

\section{Materials and Methods}

\section{Subjects}

Patients who met at least two of the three following clinical standards were diagnosed as AP bearers: abdominal pain; serum amylase above the upper reference limit of more than 3 times; positive ultrasonography or computed tomography scan. 160 patients (103 men, 57 women) diagnosed with AP in Henan Provincial People's Hospital, Henan Province, China, were recruited for this study. The study was approved by the ethical committees of Henan Provincial People's Hospital. Informed consents were obtained from all patients.

\section{Methods}

Information such as the tobacco habits and alcohol consumption of each individual was obtained from the records in the hospital or by faceto-face interviews. Blood samples of all the patients were taken within 24 hours after admission to the hospital. Serum levels of triglyceride (TG), total cholesterol (TC), high-density lipoprotein cholesterol (HDL-C), low-density lipoprotein cholesterol (LDL-C) and homocysteine were measured on an automatic biochemical analyzer (AU5400, Olympus Optical Co, Sizuoka, Japan). The patients were divided into two groups (Group 1 and Group 2) based their serum homocysteine concentration levels. Patients with high plasma homocysteine concentrations $(\mathrm{C}>15$ $\mu \mathrm{mol} / \mathrm{L}$ ) were classified as Group 1 (50 men, 25 women), while the rest with normal plasma homocysteine concentrations $(5 \mu \mathrm{mol} / \mathrm{L} \leq \mathrm{C} \leq 15$ $\mu \mathrm{mol} / \mathrm{L}$ ) were identified as Group 2 (53 men, 32 women). The clinical characteristics of Group 1 and 2 were shown in Table 1. Differences

*Corresponding author: Lian-Cai Wang, Department of Hepatobiliary Surgery, Henan Provincial People's Hospital, Zhengzhou University, China, Tel: +8637165897522; E-mail: springcoming369@163.com

Received December 17, 2015; Accepted December 22, 2015; Published January 28, 2016

Citation: Zhang LC, Li QY, Zhang JX, Wang LC (2016) Hyper-Homocysteinemia: A Potential Indicator of Acute Pancreatitis. J Bioengineer \& Biomedical Sci S3:002. doi:10.4172/2155-9538.S3-002

Copyright: $\odot 2016$ Zhang LC, et al. This is an open-access article distributed under the terms of the Creative Commons Attribution License, which permits unrestricted use, distribution, and reproduction in any medium, provided the original author and source are credited. 


\begin{tabular}{|l|c|c|c|}
\hline & Group 1 (n=75) & Group 2 (n=85) & P \\
\hline Age (year) & $45.1 \pm 15.7$ & $41.5 \pm 14.9$ & 0.14 \\
\hline BMl $\left(\mathrm{kg} / \mathrm{m}^{2}\right)$ & $25.4 \pm 4.0$ & $25.8 \pm 4.6$ & 0.66 \\
\hline Smoking $(\mathrm{n}, \%)$ & $27(36.0 \%)$ & $37(43.5 \%)$ & 0.42 \\
\hline Alcohol drinker $(\mathrm{n}, \%)$ & $26(34.7 \%)$ & $34(40.0 \%)$ & 0.52 \\
\hline Homocysteine $(\mu \mathrm{mol} / \mathrm{L})$ & $26.1 \pm 13.9$ & $10.7 \pm 2.8$ & --- \\
\hline TG $(\mathrm{mmol} / \mathrm{L})$ & $3.0 \pm 4.0$ & $4.6 \pm 5.4$ & 0.038 \\
\hline TC $(\mathrm{mmol} / \mathrm{L})$ & $4.7 \pm 1.8$ & $5.5 \pm 2.9$ & 0.046 \\
\hline HDL-C $(\mathrm{mmol} / \mathrm{L})$ & $1.1 \pm 0.5$ & $1.3 \pm 1.0$ & 0.15 \\
\hline LDL-C $(\mathrm{mmol} / \mathrm{L})$ & $2.8 \pm 1.3$ & $2.9 \pm 1.6$ & 0.51 \\
\hline Patients with hyper-TG (n, \%) & $39(52.0 \%)$ & $56(65.9 \%)$ & 0.079 \\
\hline Patients with hyper-TC (n, \%) & $19(25.3 \%)$ & $30(35.3 \%)$ & 0.23 \\
\hline Diabetes $(\mathrm{n}, \%)$ & $1(1.3 \%)$ & $6(7.1 \%)$ & 0.12 \\
\hline Hypertension $(\mathrm{n}, \%)$ & $4(5.3 \%)$ & $13(15.3 \%)$ & 0.069 \\
\hline
\end{tabular}

Table 1: Clinical characteristics of the patients in different groups.

between groups were analyzed using Student's $t$ test for continuous data and chi-square test for categorical data. The differences were regarded significant if the $P$ value did not exceed 0.05 . All analysis was performed using SPSS 19.0.

\section{Results}

\section{The association between hyper-homocysteinemia and AP}

The results were shown in Table 1 . Among all the 160 patients with AP, 75 patients ( $46.9 \%$, Group 1 ) which made up a very high percentage were identified with increased plasma homocysteine levels. There were no significant differences of age, BMI, smoking or/and drinking status, serum HDL-C and LDL-C levels between the two groups.

\section{The association between hyper-homocyteinemia and hyper- TG}

Notably, the patients in Group 1 (bearing higher plasma homocysteine levels) had lower serum TG and TC levels compared with patients in Group 2 (bearing normal plasma homocysteine levels), with $\mathrm{P}=0.038$ and $\mathrm{P}=0.046$ respectively. In the contrast, there were more patients in Group 2 bearing hyper-TG and hyper-TC than in Group 1 (65.9\%vs 52.0\%, and 35.3\%vs $25.3 \%$ respectively), despite that the differences were not large $(\mathrm{P}=0.079$ and $\mathrm{P}=0.23$ respectively).

\section{Discussion}

Among the 160 patients with AP, $59.4 \%$ of patients (95 persons) got hyper-TG, which was consistent with the previous research that people with hyper-TG were at high risk of getting AP $[8,9,13]$. And $46.9 \%$ of patients (75 persons) had higher plasma homocysteine levels, which, very possibly, indicated that higher plasma homocysteine levels could also increase the risks of suffering AP. This kind of association was rarely deeply studied and reported. Previously, Girish reported that chronic pancreatitis was associated, to some extent, with hyperhomocysteinemia, and that low folate levels maybe a key role in this derangement [12]. Yuzbasioglu reported that patients with AP had higher plasma homocysteine levels than subjects without AP [11]. The discovery in our studies that $46.9 \%$ of involved patients got hyperhomocysteinemia, was really consistent with the previous reports, and further demonstrated that a high level of plasma homocysteine is a risk factor for AP. And this high level of plasma homocysteine should be paid enough attention in the prevention of AP.

Moreover, we found that hyper-homocysteinemia and hyper-TG had no observed synergistic effects in patients with AP. Patients with hyper-homocysteinemia generally had lower TG and TC levels than those with normal homocysteine levels. According to some early reports [12,14], 5, 10-methylenetetrahydrofolate reductase (MTHFR) C677T polymorphism and low folate levels were supposed to be the main mechanism behind the up regulation of hyper-homocysteinemia in AP. Based on the mechanism, proper folate supplementation is helpful to lower homocysteine levels, resulting in the prevention of AP. And further confirmation of this hypothesis needs more studies to be done in the future.

\section{References}

1. Lankisch PG, Minoti A, Banks PA (2015) AP. Lancet 386: 85-96.

2. Bhatia M (2012) Role of hydrogen sulfide in the pathology of inflammation Scientifica 2012: 1-12.

3. Yadav D, Lowenfels AB (2013) The epidemiology of pancreatitis andpancreatic cancer. Gastroenterology 144: 1252-1261.

4. Peery AF, Dellon ES, Lund J (2012) Burden of gastrointestinal disease in the United States: 2012 update. Gastroenterology 143: 1179-1187.

5. Chuang SD, Chen KY, Xirasagar S, Tsai MC, Lin HC (2012) More than 9-times increased risk for pancreatic cancer among patients with actue pancreatitis in Chinese population. Pancreas 41: 142-146.

6. Tong GX, Gen QQ, Chai J, Cheng J, Chen PL et al. (2014) Association between pancreatitis and subsequent risk of pancreatic cancer: a systematic review of epidemiological studies. Asian Pac J Cancer Prev 15: 5029-5034.

7. Simon P, Weiss FU, Zimmer K-P, Koch HG, Lerch MM (2001) Acute and chronic pancreatitis in patients with inborn errors of metabolism. Pancreatology 1: $448-456$.

8. Valdivielso P, Bueno AR, Ewald N (2014) Current knowledge of hypertriglyceridemic pancreatitis. Eur J Inter Med 25: 689-694.

9. John S, Vijay S, Pitchumoni CS, Dhiraj Y (2014) Issues in hypertriglyceridemic pancreatitis-an update. J Clin Gastroenterol 48: 195-203.

10. Welch G, Loscalzo J (1998) Homocysteine and atherothrombosis. N Engl J Med 338: 1042-1050.

11. Yuzbasioglu MF, Ozkaya M, Cakal E, Goksu M (2008) Changes in plasma levels of homocysteine in patients with AP. JOP. J Pancreas 9: 357-361.

12. Girish BN, Vaidvanathan K, Rao NA, Rajesh G, Reshmi S, et al. (2010) Chronic pancreatitis is associated with hyper-homocysteinemia and derangements in transsulfuration and transmethylation pathways. Pancreas 39: 11-16.

13. Charlesworth A, Steger A, Crook MA (2015) AP associated with severe hypertriglyceridaemia : a retrospective cohort study. Int J Surg 23: 23-27.

14. Singh S, Choudhuri G, Kumar R, Agarwal S (2012) Association of 5,10-methylenetetrahydrofolate reductase C677T polymorphism in susceptibility to tropical chronic pancreatitis in north Indian population. Cell Mol Biol (Noisy-le-grand) 58: 122-127. 